\title{
El retorno de la democracia en Chile se priorizó el tema Presentación de Margot Loyola a la distinción Ignacio Abate Molina de la Universidad de Talca, julio 2014.
}

\author{
Sonia Montecino* \\ "La voz nos confiesa dicen, más que los gestos, más que la marcha y que...la escritura" \\ (Gabriela Mistral, en Música Araucana, 1932).
}

Me han pedido presentar, es decir "poner en presencia" a una mujer poderosa que ha recorrido el siglo XX y que nos acompaña en los inicios del siglo XXI, una mujer cuyo nombre ha circulado y se desplaza por nuestra geografía como un cuerpo en constante movimiento, una voz de múltiples tesituras, un latido de la tierra, un oleaje, un viento, un sentido. La filósofa Hanna Arendt llamó la atención sobre la diferencia entre la vida biológica (zoé) y vida para contar, para construir biografía (bios) y desde esa premisa es que Julia Kristeva sostiene que "Es muy posible que una sociedad dominada por la técnica y el beneficio, reduzca a las mujeres a ser las poseedoras de la vida "zoológica" y no favorezca la interrogación, la inquietud espiritual que constituye un "destino", una "biografía" (22) ${ }^{1}$.

Presentar es también "introducir a uno en la casa o en el trato de otro" y por eso hablaré de Margot Loyola desde la intimidad de una antigua y larga conversación que hemos sostenido en su casa, precisamente en un intento mutuo de alcanzar el bios, en un pacto femenino de decires y silencios que persigue inscribir la vida con preguntas, es decir no solamente contar una historia, sino abordarla desde sus interrogaciones, pasiones, apareceres (y uso este concepto también Arendtiano para hablar de una existencia en lo público, es decir de la presencia de una mujer, de un sujeto singular, único, en el espacio colectivo). La biografía formal de Margot Loyola puede leerse en el sitio del Fondo que lleva su nombre y algunos escritos sobre su trayectoria, por eso hoy día -que tengo el honor de "decirla"- quiero esbozar la forma en que ella misma, desde la narrativa de su "vida con sentido" trazó algunas cartografías, imágenes, búsquedas, sensibilidades y también puntos de fuga en la genealogía que la ha llevado a habitar Chile a su modo: especial y alucinado; festivo y riguroso.

¿Se imaginan ustedes lo que pueda ser organizar una transcripción de más de 100 horas de grabaciones en las cuales el relato íntimo se cruza con el "oficial", en un ejercicio de memoria y picardía, pero sobre todo de transmisión transgeneracional y de viaje interrogativo hacia el interior y exterior de una vida dedicada a "descubrir-nos" en las cuerdas más profundas de nosotros mismos?

\footnotetext{
"Académica de la Facultad de Ciencias Sociales de la Universidad de Chile.

${ }^{1}$ En Lo femenino y lo sagrado, Catherine Clement y Julia Kristeva, feminismos, Madrid, 2000.

Son obviamente también mis propias obsesiones y exploraciones las que se entreveran en este recorte, selección y puesta en escena de esta figura femenina y emblemática que hoy nos convoca en el ritual del reconocimiento que la Universidad de Talca le confiere.
} 
Hoy día tengo claro que la clave de cómo estructurarlas me la dio la propia Margot, cuando me senté por primera vez en la mesa del comedor de la casa que compartían con Osvaldo Cádiz en Exequiel Fernández con Grecia: "Yo recuerdo mi vida cortada siempre, con cuadros, cortada como a retazos". Esa palabra retazos, que proviene del antiguo catalán, y que alude a pedazos de tela o de piel, pero asimismo en su acepción de "trozo o fragmento de un razonamiento o discurso" es la que sigo en estos breves indicios y señales de la vida de Margot Loyola quiso narrarme.

\section{Genealogías cruzadas y la memoria de la letra O:}

Margot no se habla desde la cronología, sino desde una serie de emociones, preguntas y observaciones en las cuales el espacio es más poderoso que el tiempo "A mí me gusta lo que permanece, lo imperecedero, por eso amo los árboles; desde muy niña, cuando vi el angelito de mi nana Melania y tuve la sensación horrible de la muerte, esa idea me persigue, me duele, por eso quiero lo que dura, lo que es estable". Quizás porque el padre era inestable ("un andariego precioso") y la madre una presencia- que se instala en el nacimiento con el primer sonido que la niña escucha: "un llanto, un quejido" y en la piel "yo sentí muchas veces las lágrimas de mi madre que rodaban por mi frente"-, es que Margot sufre con lo que se desvanece. El padre, como buen masculino chileno, revolotea, picoflorea y la madre lo pasa mal, pero la niña también guarda sus figuras amorosas en los paseos y en los bailes: "siempre los vi bailando en la naturaleza, bailaban una cueca hermosa los dos; íbamos en trencito o victoria a Panimávida los domingos, y teníamos una vitrolita, chiquitita RCA Víctor y yo ahí los veía juntos, bailando”. En medio de esos momentos filiales aparecen las mujeres de Rari sentadas en las puertas de sus casas tejiendo sus crines y "apenas si balbuceaba y me ponía al ladito de esas artesanas, había una que sacaba una guitarra y ahí me iba yo a escuchar. Las imágenes de esas mujeres se me quedaron para siempre".

Tampoco se borran los retazos de la infancia en el "Chile profundo", en el Linares de la zona central, el nacimiento de los hermanos y cuando más grandes todos jugando al circo, al almacén; asimismo no se olvidaban las muñecas enterradas "porque siempre se morían esas muñecas que me regalaban" y los cambios permanentes de casa. También las señoritas Zerón y su colegio "que era como una quinta" bordan la entrada a la letra: "Teníamos una pizarritas en las que escribíamos y tuve que hacer la $\mathrm{O}$ y no podía hacerla, ¡me salía cuadrá! Me dio tanta angustia que lloré, guardé los cuadernos en mi bolsón y me largué a llorar. No me gustaba mucho el colegio. Después me dio por encerrar todo, escribo el 1 y lo cierro, el 2 y lo cierro. Por eso digo que pasé el OJO cuando pude hacer la $\mathrm{O}$; pero el silabario me gustaba porque gozaba con el movimiento de las letras, igual como cuando empecé a estudiar piano, me gustaba el sonido y me gustaba el dibujo de las notas en el pentagrama”.

De las hermanas Zerón, al colegio de monjas y de ahí al Liceo de Niñas de Linares y como "éramos de medio pelo todas las señoritas aprendían un instrumento, no para tocar en un escenario sino para ir a las fiestas de sociedad, para agarrar novio, para seducir". Los colegios fueron espacios donde la niña recitó poesías, bailó y cantó, sólo en inglés le va mal "porque yo no acepto otros idiomas, sino el mío, lo encuentro más clarito". La madre 
persevera en que la nińa continúe con sus clases de piano y la primera vez que toca en el Liceo lo hace con las redondas: "eso fue lo primero que toqué, una escala de cinco notas ascendiendo y descendiendo con todos los deditos".

Un nuevo cuadro: la vida en Santiago donde la madre, farmacéutica, compra una botica, y la pierde, así como pierde a Recaredo, los dos hijos hombres y su hermana se quedan con él y la nińa con ella. Horacio D'ottone le tiende una mano y la madre se instala con una nueva farmacia en Curacaví. La nińa se queda en Santiago en la casa que generosamente le abre la familia $\mathrm{D}^{\prime}$ ottone, está en sexta preparatoria y se dispone a entrar en la Normal $N^{\circ} 2$. Todos los fines de semana, las vacaciones y las fiestas viaja a Curacaví, a "una farmacia donde había una pieza grande y otra para la botica. Había un altillo, allí teníamos un brasero donde cocinábamos, era muy pobre, pero mi mamá trabajaba para ahorrar plata. Horacio D'ottone nos recogió a mí y luego a mi hermana que estaba muy enferma en su casa de Santiago en Cumming con San Pablo".

Desde ese espacio citadino emergerá un doble cuerpo: las Hermanas Loyola, el dúo que conforma con Estela, la incursión en lo público, los primeros premios como el de la Radio del Pacífico que recuerda con emoción, "éramos jovencitas, con trencitas, teníamos algo del campo que a la gente le gustó y les gustó también como cantamos "por un imposible muero, por un imposible conseguir el imposible que quiero" Comienzan los contratos, y la niña desarrolla el conocimiento "Sintiendo las cosas, el canto, la música", las luces y las opacidades que se aposarán me dice Margot en las entrańas: "Yo aprendo desde el sentimiento". Y en el proceso de conocer, lo rural y lo urbano, el campo y la ciudad serán espacios que la niña transite e internalice sin escisión, dibujándose allí la multiplicidad de caminos que asomarán más tarde: lo diverso inscrito en el desasosiego de su búsqueda. Por eso lo docto y lo popular, la radio y la academia, el rodeo y el escenario urbano van tejiendo el contrapunto de una melodía que se gestaba en el cuerpo en que la mujer Margot se iba desliando. Pero todavía era dos, una feminidad múltiple que se protegía para cruzar la frontera de lo privado (como fue usual si recordamos a las hermanas Orellana, las Acuña, las Parra): y así las hermanas Loyola van desbrozando paso a paso los complejos escenarios que lo público levanta para las mujeres, y la madre, la tercera en la escenografía, apoyando el camino de sus hijas.

"Yo elegí la música, dejé la Escuela Normal, creo que tendría unos dieciocho años. Fui a dar exámenes al Conservatorio Nacional de Música y allí se me abrieron las puertas con Armando Carvajal y su esposa Blanca Hauser que sería mi maestra y a quien debo mucho. Me encontraron condiciones y me matriculé, allí aprendí solfeo, armonía y teoría. Ahí empecé a crecer, porque antes cantaba como los pajaritos no más, cantaba porque cantaba, no sabía que era folklórico. Las hermanas Loyola ya éramos conocidas en ese entonces y una vez apareció en la Farmacia Venus, una farmacia que mi madre compró después de estar en Curacaví, Carlos Isamit y Carlos Lavín del Instituto de Investigaciones Musicales. Estaban investigando sobre el folklore y querían escucharnos. Ahí mismo desenfundamos la guitarra y comenzamos a cantar. "Nos gusta, nos gusta" dijeron y desde ese momento puedo hablar de una segunda etapa de mi vida. Fuimos guiadas por Eugenio Pereira Salas, Pablo Garrido, Isamit, nosotras entregábamos lo que sabíamos y ellos también nos daban repertorio". 
Los estudiosos de la época reúnen en la universidad a cultores y cultoras, allí es donde lo disciplinario y lo popular conviven, ahora no sin conflictos, sin preguntas en la mujer Margot que ya inicia su propia exploración desde lo sensible a lo intelectual, y en esas inquietudes indagaciones las palabras de Camila Vari la estremecen: "Si usted quiere aprender, no le voy a enseñar, vaya a los campos como yo, sacrifíquese y aprenda". Como una lluvia a cántaros se suceden los nombres de las mujeres que le abrieron caminos, en ese lazo de afidamento -como denominan las feministas italianas al gesto de las que han logrado poder y conocimientos y que apoyan a las que no los tienen-, recuerda Margot con precisión los saberes femeninos recibidos de Cristina Ventura, Blanca Hauser, Elisa Gayan, Rosita Renard, Emilia Ganard, Australia Acuña, las Hermanas Acuña, Cristina Mirand, Ester Soré, Amanda Labarca y muchas más, cada una le dona un sonido, un movimiento, una letra, un rasgueo, un ademán, un vestido, un afecto.

Lejos va quedando la niña que sufría escribiendo la letra $\mathrm{O}$, la que fue bautizada Ana Margot, Ana por su madre y Margot porque su madre amaba el tango (suturándose así en ella la pareja rota), ya "sanada" de su amor edípico "al leer Freud" me contó, y ya desligada del dúo consanguíneo, la comenzarán a llamar Margosa al interior de Arica; Maiga en los campos; Margarita en Chiloé, la Marcoyola en Isla de Pascus, la Margó en los pueblos. "A mí me gusta la Maiga" me confesó Osvaldo Cádiz una de esas tarde de otoño del 2001 en que la Carmencita nos prodigaba sus onces y Margot se quedaba en silencio quizás pensando en el sentido de la permanente mutación de las cosas.

\section{La nińa de la voz que besa}

Si la voz nos confiesa como dice Mistral, el programa de Radio que Margot inicia la define como alguien que toca u oprime con los labios, y si su voz besa, la metáfora nos acerca al cariño, a la doble llama, como designa Octavio Paz al amor. Será ese sentido amoroso el que la irá construyendo en la plural dimensión de su bios: la mujer intérprete, la investigadora, la profesora de la escuelas de temporada de la Universidad de Chile y de los conjuntos folclóricos (maestra le dicen sus discípulos), la hija, la hermana, la esposa, la amiga. La que despliega su energía capturando las claves de un territorio por descubrir, en una época en la cual las preguntas por lo chileno no pasaban por las estadísticas sino por la cultura, y esa cultura Margot la descifra desde los sujetos "Primero aprendí de los mapuches, Juan Huarapil Huaraman fue mi maestro, lo conocí cuando ese muchacho tenía 14 años y me enseñó donde sentía a su raza, y la pronunciación correcta, en el dejo preciso”. Más tarde serán los rapanui: “Felipe Riroroko y Anita Ignacia Paoa me mostraron en Santiago y después en su isla su sau sau, sus cantos; Leonardo Pakarati fue otro maestro que tuve, y descubro que todos los cantos tienen una historia; ellos eran como algas, los sentí paisaje, eran flores y pensé "este es mi paraíso, aquí me quedo". Un día, vi un hombre en una casa, estaba con el torso desnudo, había un aire tibio, se escuchaba un sau sau a lo lejos, el hombre miraba por la ventana y yo lo observaba como pensando en el paisaje, en la vida, en el universo.

En ese momento, pesco al hombre por detrás ¡no sé que me impulsó a eso! y le pregunto: ¡¿En qué piensas?! él se asusta y me responde: "Estaba mirando las gallinas que comían papa, no sabía que comían papa”, Entonces pensé: ¿No será que me iré a cansar 
de mirar gallinas comer papas? ¡Mejor me voy! Y después me acordé de un doctor que me dijo: "Somos pura hormona" y yo le contesté: "No, señor, yo voy contra las hormonas y pienso".

También en el norte la cultura viva se encarna en el relato de los viajes con quien será su pareja de siempre Osvaldo Cádiz; un nuevo cuerpo doble que acompaña y complementa la vida plural de Margot. "El primer viaje por el desierto fue entre Pica y Matilla, íbamos a la fiesta de San Antonio a ver bailar el cachimbo. ¿Vámonos a pie le dije a Osvaldo? Eran las doce y teníamos que llegar a las cinco porque empezaba a esa hora el primer cachimbo, "con la rompía del día". Empezamos a andar y me sorprendí de caminar como las mujeres de la altura, no sabía como lo hacían, pero aprendí caminando; después miré el paisaje de noche, las estrellas tan brillantes como las de Copiapó, que son las estrellas que más quiero. Eran tres cuartas partes del cielo y una cuarta parte de tierra, yo sentí la redondez de la tierra y el silencio lleno de sonidos de la pampa, yo sentía toda esa música y llegamos a las cinco de la mañana a Matilla”.

En la persecución del cachimbo, Alejandro Rivera, Irma Monje,, Maximiliano Pereira compondrán la constelación de muchas y muchos que Margot escuchó, tocó, besó, amó y valoró. Son demasiadas las voces que habitan la prodigiosa memoria de Margot, y su cuerpo el aventador que las prodiga y escribe en la partitura de la antigua chilenidad nuestra. De la isla esporádica -Rapa Nui- el archipiélago de Chiloé, donde Elsira Cabuyanca, La Chira, la recibe "llena de magia, pero también de soledades" con su voz baja y potente; de allí a la Patagonia, a ese sur que la cautivó con el grito del Zapucay "y los hombres tan lindos, tan fuertes, que te dan un poco de miedo".

Trabajo profundo en las entrañas del país, incesante búsqueda e interrogaciones que más allá de la disciplina del folklore templan el alma de una Margot que reflexiona y piensa a Chile con las herramientas de una antropóloga "Yo vi lo regional, pero vi también allí lo universal, cada pueblo tiene su estilo y su forma de bailar una misma danza, eso es maravilloso y tú vas descubriendo eso que cada uno le agrega o le quita o crea”. Esa idea la impulsa a traspasar las fronteras y a emprender viajes a Argentina y Perú, serán grandes áreas culturales intersectadas las que va palpando, sintiendo y aprehendiendo desde las comunidades, grupos o sujetos, el baile, el canto y su historia, "el contexto -me dice- es fundamental para entender un baile y un canto, aislado comunica poco, y también el ánimo, el estado de ánimo". Fraguada en el terreno con cultores y cultoras, y en el diálogo intelectual con Carlos Vega y José María Arguedas las áreas culturales se ensanchan y los recorridos de marineras, cachimbos, huainos, cuecas y zamacuecas se van hilvanando en su cuerpo y en su alma.

Y aunque los aviones no eran su predilección, comprendió que cruzar el gran charco era como un rito de pasaje a su construcción como intérprete, cantante y bailarina de folklore, y así llegó a París, a la Europa socialista y a España, en varias ocasiones, pero siempre "Cuando el avión atraviesa la cordillera ya algo me falta, algo me faltó en los escenarios de todo el mundo, algo que sólo tenían los escenarios de mi país. Por eso digo que si me quieren matar que me echen de Chile. Yo me emociono con Chile, lo quiero y se me olvidan las tonteras que a veces se hacen, sufro a Chile".

Ya no será la nińa de la voz que besa, pero rozará con su voz el siglo XX, en escenarios, discos, rodeos, ramadas, casas y campos multiplicándose sus movimientos y sus 
enseñanzas, tanto que dudo que haya un rincón donde no se sepa de Margot Loyola y se la admire y quiera ya sea como un símbolo o imagen de un sentido de "lo chileno". Porque su voz la confiesa es que ella condensa identidades y también ese indescifrable mensaje que la figura de la guitarrera, en su loza negra de Quinchamalí, ha dejado suspendido en el tiempo.

\section{Tocar las cuerdas de la tierra}

Es difícil en Chile que la escena del arte, en cualquiera de sus manifestaciones sea ocupada por más de una mujer, las fronteras del androcentrismo todavía no desaparecen y pareciera que nuestro país no soporta el genio femenino multiplicado. En el bios de Margot hay otro retazo que se torna lenguaje, afecto y dualidad. Me refiero a su vínculo con Violeta Parra.

Reflexionando sobre los lazos humanos, Margot piensa: En este campo de la amistad, es mucho más difícil encontrar una amiga, que un hombre en el terreno del amor, ¡ un hombre en la vida sí se encuentra! Pero amigas, es difícil, hay alumnas, maestras, gente que te admira..." Violeta Parra la eligió como madrina de la hija que muere mientras ella está en París, y mantienen a lo largo del tiempo una relación dialógica:" Hablábamos sobre el devenir del hombre, ella sufría de unas angustias mortales que yo no percibía, pero sí ella las mías. A veces yo le decía, siento una angustia muy grande y ella me contestaba: ; sácate esa blusa! y me colocaba agüita fresca en los brazos y me aliviaba. Nunca la vi desmayar, pero en esas conversaciones sobre la vida y la muerte me confesó:"Uno tiene que escoger el momento de su muerte, uno tiene que imponerlo" Eso fue mucho antes que decidiera suicidarse".

Un vínculo gemelar, pero también de complemento y tensión de dos fuerzas femeninas: Jodorowsky, en París, le comentó a Margot a propósito de ambas:"Violeta es la cantora de la muerte o de los colores oscuros, y usted es la vida, el arcoíris", Violeta tenía su verdad y yo la mía - continuaba Margot- pero nos unía que ambas verdades venían del pueblo, nos dolía el pueblo.

Éramos diferentes en el canto, a ella no le gustaba mi voz porque era muy hermosa y formada en el rigor de la academia, eso no le gustaba, pero yo le decía: prefiero tener esa voz, a mí me gusta que corra la voz, que se sienta, yo me libero en el canto y a usted le duele el canto" Violeta le dijo: acá en París usted no llegará a ningún lado con esa voz". Pero Margot llegó a la Sorbonne- y mucho más allá en Europa-; siendo elogiosamente presentada por Alfred Metraux, desplegó los bailes y cantos Rapa Nui en un escenario colmado de público.

"Yo fui siempre modesta -proseguía narrando Margot- y ella un poco menos modesta, tal vez por su genialidad. Un día me dijo: bueno, comadre yo tampoco toco las cuerdas del mundo, y le respondí: yo quisiera tocar bien una sola cuerda, no aspiro a más".

Ese deseo de Margot se ha cumplido tocando, desde mi mirada, las cuerdas de la tierra, esas que le seguimos escuchando por ejemplo, en los sonidos de El Parcito, jóvenes recientemente premiados por el Altazor, y que han seguido su aprendizaje y el de Osvaldo, rozando, besando, eso que ha sido el hilo conductor de su bios: la permanencia en el cambio, el sentido de lo duradero: "Yo parto de la eternidad, mi hijita, del amor absoluto 
y de la perfección en el arte. No siempre se logra, pero esos principios me han guiado el sentimiento", y qué duda cabe: cuando Margot ha perseguido hasta el último giro de un pañuelo, de un paso, de un canto, trae al presente quizás qué antigua mano, cuerpo y voz de un hombre y una mujer en una larga duración que nos envuelve en las premisas de su rasgar de cuerdas de la tierra.

Desde allí la "otra", la amiga, la colega, la comadre Violeta permanecerá también adosada a los pedazos de piel, a la vida con sentido de Margot, en duelos cuequeros y sueńos conjurados donde una llama a la otra como en los peumos mapuches. Chile tendrá que resistir la fuerza femenina doble de lo oscuro y el arcoíris, para así propiciar más allá de lo gemelar, lo múltiple que aunque excluido de los imaginarios oficiales portan las mujeres que dedican su existencia al arte.

\section{El cuerpo a cuerpo con Chile: epistemología de la cueca}

Margot ¿cómo percibes a Chile después de haberlo caminado, estudiado y querido desde casi un siglo? le pregunté después de un almuerzo pródigo cocinado por Carmencita el verano del 2002. "Es una danza que viene desde la cabeza que está en la Patagonia, el corazón e la zona central y las piernas en el norte" Entonces Chile se mueve le comento: "Sí ¿no lo sientes?” Y la conversación se deslizó hacia el inconsciente donde la narración onírica dio paso a una pregunta por las identidades:"tuve un sueño tan lindo hace unos días -ya te conté de mis pesadillas de siempre-, un sueño con colores, con un jardín maravilloso lleno de luces y de flores bellísimas y allí había una familia que conocí hace mucho en el campo, estaban todos lindos, vestidos de blanco. Y los llamé después para agradecerles porque ellos me enseñaron una tonada, y después me quedé pensando en una pregunta que siempre me hacen:

- ¿Dónde se siente usted mejor?

- Cantando, les respondo.

- Pero ¿qué le gusta más?

- Bueno yo me siento bien en todo Chile, porque pertenezco a Chile.

Pero, he de ser sincera mi identidad yo la siento en la tonada y en la cueca, porque con la tonada he ido conociendo a la gente del centro, del sur, y con la cueca: todo Chile me ha hablado en la cueca".

Ahí emerge el último retazo que traeré a esta presentación, la cueca como algo indisoluble de Margot, quizás el argumento más sólido de su biografía, el que se entrevera como un boqui, un cabello de ángel, un copihue, en su narrativa, en su pasión y en su reflexión. Se trata de la cueca como expresión cultural que define las relaciones entre hombres y mujeres, ese sitio desde donde parte la vida y el amor, pero con las complejas cuerdas de la tierra que Margot sabe tocar nada es simple: "¡Ay cuántas cuecas he bailado! ;Yo creo que el único hombre que no ha bailado conmigo es el Papa! ¡He bailado con príncipes, con el hombre más pobre y más humilde de la montaña. Son diferentes cuecas, yo no puedo bailar igual. La última cueca fue en unos andurriales, era una fiesta pobre, triste, yo bailé con un hombre con ojotas, una mujer tocaba una guitarra y cantaba 
solita. Ahí yo no pude bailar mi cueca que se llama "las enfadadas" porque el otro no podía defenderse. Y yo donde voy me transformo, soy la "otra" y empiezo a cantar y bailar como lo hacen en el lugar en que me encuentro".

Así habita la Margot intérprete, mimética al entorno, que cristaliza en su cuerpo las identidades de los "otros" en la genialidad de la traductora que no traiciona. Recuerda, además con precisión las cuecas que ha bailado y con quién, una de ellas en Colombia con Osvaldo, una cueca de velorio, luego de haber hablado de las diversas variaciones chilenas; también una en Pisagua con un preso político en el gobierno de González Videla, otra en un rodeo cuando era parte de las Hermanas Loyola y así.

"Pero cuando generalmente estoy yo es cuando bailo con mi marido. La cueca es un duelo: la mujer y el hombre en igualdad y jveamos quien tiene la capacidad de decir lo que tiene que decir! Siempre soy desafiante frente a él y ¡no debería serlo! Pero, él sabe defenderse y sabe acompañarme, por eso la gente nos aplaude tanto. Esa cueca mía tiene varias sonrisas, varias formas de tomar la falda, una cueca asentada, profunda y vibrante donde yo entrego toda mi agresividad frente al hombre. A pesar de ser mi marido tan bueno yo sigo siendo agresiva porque en la cueca yo me transfiguro en las otras mujeres, en las pobres, en mis amigas que engañan, ¡bailo por todas las engañadas!!”

La cueca desafiante dice haberla aprendido en los rodeos, donde se baila con hombres a los cuales hay que demostrar que no se es mujer subordinada... Pero en la epístame de la cueca está el contexto: "cerca del mar la coreografía es más abierta" y en la montańa "es oprimida por los cerros, con desplazamientos chiquititos y la mirada puesta en el infinito". En el rodeo el huaso es arrogante, a veces viene de ganar el champion: "Una vez bailé con uno grande y altivo, me ordenó con el pañuelo y en cada vuelta como que chicoteaba, me parecía estar bailando no con un hombre sino con un animal que me aplastaba. En esa cueca estaba bailando él, no yo, era el gran dueño del fundo, al que dominaba.

Otra vez me tocó un hombre que me hacía cachaña, como que me iba a pegar, y le pregunté: ¿y usted qué hace mijito? Soy boxeador, me contestó.

Así el poder, las relaciones de género, los oficios y la dominación masculina de la hacienda puede leerse en este modo de asir el baile nacional. Un jalón de la biografía de Margot está en su cuerpo a cuerpo con la cueca.

Más allá del baile como duelo y goce, habrá coordenadas para comprenderlo y reflexionar sobre la vida a partir de él: "La cueca es amatoria, es el amor, y me pregunto ¿Cuándo la madre baila con el hijo y el padre con la hija? Allí no puede haber el amor pasional que define a la cueca. Está el amor filial, pero también está el amor a la patria, al paisaje, a la historia, está el conflicto, las clases, las diferencias. Por eso la cueca no se trata de esa linda historia del gallito, la gallina, la potranca ¡ ${ }_{\mathfrak{N}} \mathrm{No}$, señor, es historia, conflicto, epopeya!"

En la idea de esta presentación fragmentaria y de "introducir a uno en la casa del otro", les cuento que Delia Domínguez le dijo a Margot: "Loyola Margot maulina de maderas nobles donde las guitarras nacionales se quedaron a vivir para siempre" y Pablo Neruda en una invitación a su casa de los Guindos, la llamó "voz y tierra de Chile" y su madre Ana Palacios: "Hija adorada, este mes de septiembre es sinónimo de Margot Loyola”. 
Ya retornaremos en otra ocasión a los retazos, a la piel de las manos de la niña que no podía dibujar la $\mathrm{O}$ y que se impresionó cuando vio o creyó ver a Gabriela Mistral visitando su colegio de Linares "imponente y de ojos bellos", a la mujer que ha poblado, con su voz, es decir con su confesión, los profundos pliegues de la chilenidad vieja haciendo posible que hoy podamos preguntarnos y asombrarnos junto a ella de lo que permanece a pesar de todo. Si el nombre propio define una identidad y un aparecer, la Margosa de Belén, la Maiga de los campos del Chile Central; la Margarita chilota, la Margó del pueblo citadino, son nombres que muestran las plurales cuerdas de nuestra homenajeada. A mí me gusta la Marcoyola que permanece danzando en la marea, ella misma como isla esporádica, no sujeta a ningún viento. 